\title{
Is Female Sex an Independent Predictor of In-Hospital Mortality in Acute Myocardial Infarction?
}

\author{
Lúcia Pimenta, Roberto Bassan, Alfredo Potsch, José Francisco Soares, Francisco Manes Albanesi Filho \\ Rio de Janeiro, RJ - Brazil
}

Objective - To assess whether female sex is a factor independently related to in-hospital mortality in acute myocardial infarction.

Methods - Of 600 consecutive patients (435 males and 165 females) with acute myocardial infarction, we studied 13 demographic and clinical variables obtained at the time of hospital admission through uni-and multivariate analysis, and analyzed their relation to in-hospital death.

Results - Females were older $(p<0.001)$ and had a higher incidence of hypertension $(p<0.001)$. Males were more frequently smokers $(p<0.001)$. The remaining risk factors had a similar incidence among both sexes. All variables underwent uni- and multivariate analysis. Through univariate analysis, the following variables were found to be associated with in-hospital death: female sex $(p<0.001)$, age $>70$ years $(p<0.001)$, the presence of previous coronary artery disease $(p=0.0004)$, previous myocardial infarction $(p<0.001)$, infarction in the anterior wall ( $p=0.007)$, presence of left ventricular dysfunction $(p<0.001)$, and the absence of thrombolytic therapy $(p=0.04)$. Through the multivariate analysis of logistic regression, the following variables were associated with inhospital mortality: female sex ( $p=0.001)$, age $(p=0.008)$, the presence of previous myocardial infarction $(p=0.02)$, and left ventricular dysfunction $(p<0.001)$.

Conclusion - After adjusting for all risk variables, female sex proved to be a variable independently related to in-hospital mortality in acute myocardial infarction.

Key words: female sex, in-hospital mortality, acute myocardial infarction

Hospital Pró-Cardíaco and Universidade Estadual do Rio de Janeiro Mailing address: Lúcia Pimenta - Pró-Cardíaco - Rua Dona Mariana, 219 22280-020 - Rio de Janeiro, RJ, Brazil - e-mail: lucia-pimenta@uol.com.br English version by Stela Maris C. e Gandour
Cardiovascular disease is the major cause of death in industrialized countries, acute myocardial infarction being its major representative ${ }^{1}$. Official mortality statistics in our country show a difference regarding the sexes ${ }^{2}$. Males comprise the most victims of the disease in the entire world. Brazilian females, on the other hand, have an elevated risk of death, much higher than that in other places, particularly in the age bracket from 45 to 64 years ${ }^{3}$. Approximately 1 in every 2 females will die due to acute myocardial infarction or cerebral stroke, far exceeding mortality due to all combined types of neoplasias ${ }^{4}$.

Most epidemiological studies about morbidity and mortality due to coronary artery disease have been based on male models, and their results have been extrapolated to the female population ${ }^{5}$. The possibility that the female sex may have peculiarities regarding risk factors, disease presentation, and prognosis has only recently been suggested ${ }^{6}$.

Our study aims to analyze in-hospital mortality due to acute myocardial infarction regarding sex based on demographic and clinical characteristics at the time of hospital admission. We also aimed to identify the variables associated with in-hospital mortality, and whether, after adjustments for all risk variables, female sex is a factor independently related to in-hospital mortality.

\section{Methods}

We carried out a prospective study from January ' 91 to December' 92 and from November' 93 to June '96 with 600 consecutive patients diagnosed with acute myocardial infarction, who sought a private hospital for primary and tertiary emergency care in the city of Rio de Janeiro. In the first and second phases of the study, 347 and 253 patients were respectively analyzed. At the time of hospital admission, we collected demographic data, the clinical history, the physical examination, and performed an initial electrocardiography in each patient, as had been previously established. The diagnosis of acute myocardial infarction was defined by the presence of at least 2 out of the 3 following criteria: 1) clinical criterion: presence of chest pain sugges- 
ting acute coronary heart disease with a minimum duration of 30 minutes; 2) electrocardiographic criterion: presence of elevation of the J-ST segment in at least 2 contiguous leads ( $1 \mathrm{~mm}$ in the leads of the frontal plane and $2 \mathrm{~mm}$ in the leads of the horizontal plane); 3) enzymatic criterion: elevation of the serum levels of the creatine phosphokinase enzyme (CK) and its myocardial fraction (CK-MB) observed at least in 2 serial measurements in the first 24 hours of evolution of acute myocardial infarction with a typical fall; CK-MB levels should be $10 \%$ higher than those of total CK.

Data consisted of dichotomous, polychotomous, and continuous variables. The response of interest was in-hospital death. The dichotomous variables were sex, hypertension, tobacco use, diabetes mellitus, familial history of coronary artery disease, previous myocardial infarction, previous coronary artery disease, hypercholesterolemia, use of thrombolytic therapy, and electrocardiographic location of the infarct site defined as the inferior, anterior, or lateral wall, or absence of the Q-wave. Left ventricular dysfunction classified according to the Killip-Kimball heart failure classification was treated as a polychotomous variable and ranged from 1 to 4 . The continuous variables were age and $\Delta \mathrm{t}$ interval. The results of the continuous variables were presented as their mean value and respective standard deviation. For analyzing the relation between the continuous variables and in-hospital mortality, the continuous variables were transformed into dichotomous variables (age $>70$ years and $\Delta \mathrm{t}>120 \mathrm{~min}$ ). The diverse variables of the study were analyzed with the statistical program SPSS for version 6.0 of MS Windows.

To determine the statistical significance of the differences between the proportions, the chi-square test was used; for differences between the means of independent samples, the Student $t$ test was used. The Cochran test was used to verify the existence of a linear trend between the Killip-Kimball heart failure classification and death. Univariate analysis was used to compare the in-hospital mortality rate between individuals with and without a certain variable. Odds ratio $(\mathrm{OR})$ was used as a measure of association. The pre-established level of significance was $5 \%$. To assess the statistical significance of the association, the null hypothesis was $\mathrm{OR}=1$.

For age adjustment, the Mantel-Haenszel test was used. The measure of association used was the relative risk (RR). Aiming to avoid incorrect inferences due to confounding factors, the patients were subdivided into homogeneous extracts of age bracket, at 10-year intervals.

Data were also subjected to multivariate analysis of logistic regression. Therefore, the variables age and KillipKimball heart failure classification were treated as continuous, and the remaining as binary. As the step-by-step approach to build the regression model was used, the superior threshold for $p$ at entrance and exit was established as 0.15 and 0.10 , respectively.

\section{Results}

The demographic and clinical characteristics of the population studied are shown in tables I and II.

\begin{tabular}{|lcc|}
\hline $\begin{array}{c}\text { Table I - Demographic characteristics of the global population of } \\
\text { patients with acute myocardial infarction }\end{array}$ \\
\hline Characteristics & Number & $\%$ \\
\hline Age (years) & $64.6 \pm 13.4$ & \\
Male sex & 435 & $72.5 \%$ \\
Hypertension & 289 & $48.2 \%$ \\
Diabetes mellitus & 99 & $16.5 \%$ \\
Hypercholesterolemia & 211 & $35.2 \%$ \\
Tobacco use & 229 & $38.2 \%$ \\
Familial hist of coronary artery disease & 263 & $43.9 \%$ \\
Previous infarction & 111 & $18.5 \%$ \\
Previous coronary artery disease & 181 & $30.2 \%$ \\
\hline
\end{tabular}

\begin{tabular}{|lcc|}
\hline \multicolumn{2}{|c|}{$\begin{array}{c}\text { Table II }- \text { Clinical characteristics of the global population of } \\
\text { patients with acute myocardial infarction }\end{array}$} \\
\hline Characteristics & Number & $\%$ \\
\hline$\Delta \mathrm{t}(\mathrm{h})$ & $4.85 \pm 7.11$ & \\
Thrombolytic agent use & 239 & $39.8 \%$ \\
Infarct location & & \\
Inferior wall & 234 & $39.0 \%$ \\
Anterior wall & 223 & $37.2 \%$ \\
Lateral wall & 017 & $2.80 \%$ \\
No "Q" wave & 126 & $21.0 \%$ \\
Ventricular dysfunction & & \\
Killip-Kimball class I & 506 & $84.3 \%$ \\
Killip-Kimball class II & 060 & $10.0 \%$ \\
Killip-Kimball class III & 020 & $3.30 \%$ \\
Killip-Kimball class IV & 014 & $2.30 \%$ \\
\hline
\end{tabular}

Most patients (72.5\%) were males in a proportion of 2.6:1. Females were significantly older, by a mean of 8 years. The risk factors for developing coronary artery disease did not differ between the sexes, except for a higher prevalence of hypertension in females and tobacco use in males (Table III).

The time interval between symptom onset and arrival at the emergency department ( $\Delta$ t interval) was greater for females than for males, being $5.46 \pm 7.23$ hours and $4.6 \pm 7.06$ hours, respectively; this difference, however, did not reach statistical significance. When analyzing the groups with $\Delta \mathrm{t}$ interval up to 2 hours, we observed that a lower contingent of females than of males arrived earlier at the hospital $(36.5 \%$ and $48.6 \%$, respectively); this difference, however, was statistically significant $(\mathrm{p}=0.007)$. No difference between the

\begin{tabular}{|lccc|}
\hline \multicolumn{4}{|c|}{ Table III - $\begin{array}{c}\text { Demographic characteristics of the population } \\
\text { differentiated by sex }\end{array}$} \\
\hline Variables & Males & Females & p value \\
\hline Age & $62.2 \pm 13.2$ & $70.9 \pm 11.8$ & $<0.001$ \\
Hypertension & $41.8 \%$ & $64.8 \%$ & $<0.001$ \\
Diabetes mellitus & $16.3 \%$ & $16.9 \%$ & $\mathrm{~ns}$ \\
Hypercholesterolemia & $36.3 \%$ & $32.1 \%$ & $\mathrm{~ns}$ \\
Tobacco use & $43.7 \%$ & $23.6 \%$ & $<0.001$ \\
Familial history of & $44.1 \%$ & $43.0 \%$ & $\mathrm{~ns}$ \\
coronary artery disease & & & \\
Previous coronary artery disease & $29.2 \%$ & $32.1 \%$ & $\mathrm{~ns}$ \\
Previous myocardial infarction & $18.9 \%$ & $17.6 \%$ & $\mathrm{~ns}$ \\
\hline
\end{tabular}


sexes was observed regarding the location of myocardial infarct. Most patients were admitted to the hospital in KillipKimball heart failure classification I. However, a higher prevalence of females admitted in Killip-Kimball heart failure classification II was observed. The thrombolytic therapy was used more frequently in males than in females (Table IV).

Global in-hospital mortality was $13.5 \%$; in-hospital mortality being significantly higher $(\mathrm{p}<0.001)$ in the female $\operatorname{sex}(23.0 \%)$ as compared with that in the male sex $(9.9 \%)$.

In univariate analysis, the variables associated with inhospital mortality were as follows: age above 70 years ( $\mathrm{p}<0.001 ; \mathrm{OR}=4.21)$, the female $\operatorname{sex}(\mathrm{p}=0.001 ; \mathrm{OR}=2.73)$, hypercholesterolemia $(\mathrm{p}=0.008 ; 0 \mathrm{R}=0.48)$, familial history of coronary artery disease $(\mathrm{p}=0.001 ; \mathrm{OR}=0.37)$, tobacco use $(\mathrm{p}=0.001 ; \mathrm{OR}=0.32)$, previous coronary artery disease ( $\mathrm{p}=0.0004 ; \mathrm{OR}=2.32)$, previous myocardial infarction ( $\mathrm{p}<0.001 ; \mathrm{OR}=2.97)$, use of thrombolytic therapy $(\mathrm{p}=0.04$; $\mathrm{OR}=0.6)$, infarct located in the anterior wall $(\mathrm{p}=0.007$; $\mathrm{OR}=1.90)$, infarct located in the inferior wall $(\mathrm{p}=0.002$; $\mathrm{OR}=0.43$ ), and left ventricular dysfunction ( $\mathrm{p}<0.001$; $\mathrm{OR}=10.26$ ). Knowing that for assessing the statistical significance of the association the null hypothesis was $\mathrm{OR}=1$, those variables with $\mathrm{OR}<1$ were associated with a reduction in the risk of mortality. The remaining variables did not correlate with the response of interest.

In regard to the adjustment of in-hospital mortality to age, we have the following scenario. As females had acute myocardial infarction later than males did (a mean of 8 years of delay), advanced age was predicted as the major explanation for the worse survival of the female sex. For assessing this hypothesis, mortality was adjusted for age using the MantelHaenszel test (Table V). The patients were divided by sex into 5 homogeneous extracts according to the age bracket. We observed that, even though statistical significance was not obtained between the differences of each isolated age bracket, the total effect existed and was kept the same after correction, confirming the higher mortality among females as compared with males, independently of age $(\mathrm{p}=0.02)$.

In multivariate analysis of logistic regression, all previously established demographic and clinical variables were included. The $\Delta t$ interval variable was not included in this phase of the analysis because it was available only in 445

\begin{tabular}{|c|c|c|c|}
\hline \multicolumn{4}{|c|}{$\begin{array}{l}\text { Table IV - Clinical characteristics of the population differentia- } \\
\text { ted by sex }\end{array}$} \\
\hline Variables & Males & Females & $\mathrm{p}$ value \\
\hline \multicolumn{4}{|l|}{ Infarct location } \\
\hline Inferior wall & $40.2 \%$ & $35.8 \%$ & Ns \\
\hline Anterior wall & $36.3 \%$ & $39.4 \%$ & $\mathrm{Ns}$ \\
\hline Lateral wall & $2.7 \%$ & $3.0 \%$ & Ns \\
\hline No "Q" wave & $20.7 \%$ & $21.8 \%$ & Ns \\
\hline \multicolumn{4}{|l|}{ Ventricular dysfunction } \\
\hline Killip-Kimball class I & $86.2 \%$ & $80.0 \%$ & $\mathrm{Ns}$ \\
\hline C Killip-Kimball class II & $8.3 \%$ & $14.5 \%$ & 0.02 \\
\hline Killip-Kimball class III & $3.7 \%$ & $2.4 \%$ & Ns \\
\hline Killip-Kimball class IV & $1.8 \%$ & $3.0 \%$ & $\mathrm{Ns}$ \\
\hline Thrombolytic agent use & $43.2 \%$ & $31.0 \%$ & 0.005 \\
\hline
\end{tabular}

patients, which would reduce the size of the sample to be analyzed.

We observed as independently related to in-hospital mortality the following variables: age, the male sex, and Killip-Kimball heart failure classification $>1$ (Table VI). The presence of previous myocardial infarction was a marginal variable $(\mathrm{p}=0.06)$.

Even though age had a lower OR, it is a very expressive variable, because by being continuous, it allows the growth of the coefficient in each additional year. It is worth noting that the male sex has a negative coefficient, which indicates an inverse relation with the response being assessed. Therefore, the female sex is associated with higher in-hospital mortality.

Interactions between sex and pertinent clinical variables were tested and none of them proved statistically significant.

We observed that in nonadjusted (univariate) and in adjusted (multivariate) analyses, the associations involving mortality and female sex reached statistical significance, indicating a higher risk for females. Therefore, these data provide evidence that the female sex is, by itself, an important independent predictor of in-hospital mortality from myocardial infarction.

\section{Discussion}

For many years, morbidity and mortality in coronary artery disease have been reported as occurring 5 to 10 years later in females than in males ${ }^{7-12}$. An important paradox has been reported in several studies, when acute myocardial infarction occurs: females have a higher in-hospital mortality ${ }^{5,6,13-15}$. However, in other studies ${ }^{10,16,17}$, the mortality reported is similar or even lower among females. Different methodologies applied, the varied inclusion criteria used, and the type of study (prospective or retrospective) account for these conflicting data.

In our study, we observed that females with acute myocardial infarction have significantly higher in-hospital mortality (2.3-fold) than males do.

Whether this worse prognosis in the female sex is in fact due to a biological factor or to a methodological bias is still a matter of discussion ${ }^{18,19}$. Confounding factors, such as advanced age and a higher incidence of comorbidity, may influence the prognosis and, once corrected or adjusted, the results previously obtained no longer exist, mortality being equivalent for both sexes ${ }^{18,19}$.

Aiming at assessing these hypotheses, we carried out a prospective study in 600 consecutive patients at a single private hospital in the city of Rio de Janeiro. We analyzed 13 variables obtained from the clinical history, the physical examination, and from electrocardiographic data, which were easily collected at the time of hospital admission, and we assessed their relation to in-hospital mortality. Data were subjected to nonadjusted and adjusted analyses, so all preestablished risk variables would have their effects corrected, avoiding methodological bias. Therefore, the presence 


\begin{tabular}{|c|c|c|c|c|c|c|c|}
\hline \multirow[t]{2}{*}{ Age (years) } & \multicolumn{2}{|c|}{ Males } & \multicolumn{2}{|c|}{ Females } & \multirow[t]{2}{*}{$\mathrm{RR}$} & \multirow[t]{2}{*}{$95 \% \mathrm{CI}$} & \multirow[t]{2}{*}{$\mathrm{p}$ value } \\
\hline & $\mathrm{n}$ & $\%$ & $\mathrm{n}$ & $\%$ & & & \\
\hline$\leq 50(\mathrm{n}=109)$ & $2 / 97$ & 2.1 & $2 / 12$ & 16.7 & 0.10 & $(0.0090-1.2027)$ & 0.086 \\
\hline $51-60(\mathrm{n}=110)$ & $5 / 97$ & 5.2 & $1 / 13$ & 7.7 & 0.65 & $(0.0628-16.0309)$ & 0.79 \\
\hline $61-70(n=167)$ & $11 / 117$ & 9.4 & $7 / 50$ & 14 & 0.63 & $(0.2104-1.9681)$ & 0.55 \\
\hline $71-80(n=140)$ & $14 / 85$ & 16.5 & $17 / 55$ & 30.9 & 0.44 & $(0.1814-1.0654)$ & 0.073 \\
\hline$\geq 81(\mathrm{n}=74)$ & $11 / 39$ & 28.2 & $11 / 35$ & 31.4 & 0.85 & $(0.2815-2.6062)$ & 0.96 \\
\hline Total $(n=600)$ & $43 / 435$ & 9.9 & $38 / 165$ & 23.0 & 0.37 & $(0.2207-0.6091)$ & 0.0000 \\
\hline Adjusted & & & & & 0.55 & $(0.3172-0.9305)$ & 0.02 \\
\hline
\end{tabular}

\begin{tabular}{|lrrrrrc|}
\hline \multicolumn{7}{|c|}{ Table VI - Variables related to in-hospital mortality through the } \\
logistic regression analysis
\end{tabular}

or absence of the so-called biological factor of the female sex could be correctly assessed.

Most patients were males in a proportion of 2.6 males to 1 female, as in other great epidemiological studies ${ }^{20}$. At the time of acute myocardial infarction, in addition to the more advanced age (mean of 8 years in the population studied), females had a higher association with hypertension, which turned them into a higher risk group for mortality, according to a few reports ${ }^{6,8,13,16,21}$. On the other hand, males exhibited a higher incidence of tobacco use, as in most studies, which has been surprisingly related to lower in-hospital mortality in acute myocardial infarction ${ }^{22-25}$. Gottlieb et $\mathrm{al}^{22}$ attribute the better prognosis of smokers to their lower age and their more favorable risk profile, and not to any real benefit of tobacco use. We observed a similar prevalence (around 16\%) of diabetes mellitus for males and females, in disagreement with the literature that shows a higher prevalence in the female $\operatorname{sex}^{6,8,13,16,21}$.

Studies analyzing the clinical characteristics have shown that females more often than males have congestive heart failure, both at the time of hospital admission and during hospital evolution of acute myocardial infarction ${ }^{5,6,12,15,18,21,26-28}$.Contrary to these observations, studies including assessment of left ventricular dysfunction showed that females had a higher ejection fraction than did males ${ }^{15,26}$. Hemodynamic disorders are supposedly derived from diastolic dysfunction, which is triggered by the highest incidence of hypertension and diabetes mellitus $5,12,13,27$. Attempts exist to correlate the findings of better left ventricular function with data on coronary anatomy. Hochman et al ${ }^{12}$ reported that females have less extensive coronary artery lesions and a lower degree of fixed coronary artery obstructions, maintaining, therefore, a better ejection fraction. Behar et al ${ }^{27}$, on the other hand, attributed the preservation of left ventricular function to a more prominent collateral circulation, because the coronary artery lesions found were more severe. In our study, we did not confirm the higher incidence of left ventricular dysfunction in females. The diagnosis of heart failure was exclusively based on clinical criteria (Killip-Kimball heart failure classification), which could constitute a limitation, in addition to patients being assessed only at the time of hospital admission. We found a similar incidence for both sexes. Most patients were admitted in Killip-Kimball heart failure classification I ( $86 \%$ of the males and $80 \%$ of the females). Even knowing that left ventricular dysfunction, when present in acute myocardial infarction, brings with it a high risk for mortality, differences in its incidence could not explain the inequalities between the sexes in regard to mortality. Only in the studies by Tofler et al ${ }^{15}$ and Lincoff et al ${ }^{26}$, was the assessment of left ventricular function performed at the time of hospital admission. In the remaining studies, this assessment was performed later, which may have interfered with the results. Until the present time, no clear demonstration exists that females with acute myocardial infarction have poorer ventricular function. The role of diastolic dysfunction in the genesis of the symptoms of congestive heart failure remains speculative, because no study was carried out aiming at observing this fact.

Unequal in-hospital management could also account for different mortality rates between sexes ${ }^{9}$. Females are reported to be less aggressively approached than males are, ranging from the lower probability of admission to a coronary unit to the possibility of undergoing coronary angiography, even if the probability of ischemia is equivalent for males and females ${ }^{9,29}$. Males are traditionally known as higher risk individuals. Eligibility for thrombolytic therapy in patients with acute myocardial infarction is suggested to be different depending on the sex. In the Western Washington Emergency Department, r-TPA, only $16 \%$ of the females as compared with $25 \%$ of the males were eligible for thrombolysis, and among those eligible, only $55 \%$ of the females as compared with $78 \%$ of the males effectively received this medication ${ }^{30,31}$. 
Even though the efficacy of thrombolytic agents has been well established in restoring arterial patency, in preserving left ventricular function, and in reducing mortality, the responses to the different methods of revascularization and reperfusion in females have not been well demonstrated ${ }^{32}$. Previous analyses of great clinical trials, such as the GISSI2 (Gruppo Italiano per lo Studio della Sopravivenza Nell' Infarto Miocardioco) ${ }^{33}$, the ISIS-2 (Second International Study of Infarct Survival) ${ }^{34}$, and the ASSET (Anglo-Scandinavian Study of Early Thrombolysis) ${ }^{35}$ showed that females had a lower reduction in mortality, when compared with the placebo group, than males did. Lincoff et a ${ }^{26}$ reported that the differences disappeared after an adjustment for risk variables, with a similar benefit for both sexes. The TIMI II Study (Thrombolysis in Myocardial Infarction Phase II) ${ }^{36}$, however, provided valuable information when investigating the potential influence of sex in the results after acute myocardial infarction. Independent of the strategy adopted in acute myocardial infarction, conservative or interventionist, females had higher mortality, and this cannot be explained by the higher prevalence of risk variable ${ }^{36}$.

We observed that females had a significantly lower rate of thrombolytic therapy than males did (31\% against $43.2 \%$ ), which could be partially explained by the advanced age of the females studied (mean of 71 years), and, in addition, we should not forget that females arrived later $( \pm 60$ $\mathrm{min}$ ) at the hospital. With a cut in the $\Delta \mathrm{t}$ interval at the secon$\mathrm{d}$ hour, we observed that a significantly lower number of females had arrived at the emergency department. This delay may perhaps have influenced the indication for the use of thrombolysis, determining a loss in the opportunity to access the benefits of thrombolysis.

Several authors ${ }^{11,36}$ have shown that the late arrival at the hospital after chest pain onset was the major reason for ineligibility of females for thrombolytic therapy. Other reasons are also reported as follows: advanced age; a higher prevalence of comorbid conditions, such as hypertension, diabetes mellitus, and congestive heart failure; undervaluation or negation of the symptoms; and atypical initial clinical findings of acute myocardial infarction ${ }^{19,26,31,37}$.

This preselection regarding the use of thrombolytic agents, which does not favor females, may explain part of the difference in regard to mortality. However, the fact that no reduction in mortality among females using thrombolytic agents was observed makes us believe that the nonuse of those agents did not account for the higher mortality in the female sex, suggesting that intrinsic factors related to sex may exist, interfering with the thrombolytic response.

To establish whether the higher in-hospital mortality rate for females with acute myocardial infarction is exclusively determined by the difference in sex and not by the differences in prevalence of the risk variables, we used univariate and multivariate analysis. We also used the isolated adjustment of mortality to age, which is potentially the major factor of confusion, because the remaining risk variables did not show great differences between the sexes.

Initially, we used the univariate analysis of the global population to determine which demographic and clinical variables obtained at the time of hospital admission would be associated with a higher in-hospital mortality rate. The female sex was identified as a risk variable, the fourth in importance, being surpassed only by the classically recognized variables: left ventricular dysfunction, advanced age, and the presence of previous acute myocardial infarction.

Knowing the limitations of a method in which variables are not adjusted for, such as univariate analysis, the pre-established data were subjected to multivariate analysis of logistic regression, in which the interactions between the diverse variables were corrected. Therefore, the pure effect of each variable in the response of interest, which in our case was in-hospital death, could be determined. We confirmed the results obtained in the univariate analysis: female sex was solidly identified as an important isolated predictive factor of in-hospital death in acute myocardial infarction, the second in degree of importance ( $\mathrm{OR}=2.6)$, being surpassed only by the presence of left ventricular dysfunction.

The degree of left ventricular dysfunction represented by Killip-Kimball heart failure classifications II, III, and IV was individually the major factor for predicting in-hospital death in males and females. Patients in Killip-Kimball heart failure classification I had a mortality rate of $6.3 \%$; those in classifications II and III had mortality rates reaching 45\%; and those in classification IV had mortality rates reaching $92.9 \%$. The OR ranged from 7.03 to 171.39 for classifications ranging from II to IV. In the model proposed by Lee et al ${ }^{38}$, left ventricular dysfunction was also present, with OR ranging from 2.9 to 25.7 for the mentioned classifications.

The highest mortality among patients with previous acute myocardial infarction, as compared with those having their first infarction, has already been reported previously in several studies ${ }^{13,15,39}$, because of the higher predisposition to ventricular dysfunction and cardiogenic shock at the time of hospital admission. In the univariate analysis, the importance of the previous acute myocardial infarction could be felt, increasing the chance of death by 2.97 times (OR).

As in most studies ${ }^{40,41}$, advanced age proved to be an important independent predictive factor of mortality. This piece of information is easily obtained and may identify high-risk patients, who may benefit from a more aggressive therapy. As a refinement of the statistical method, we checked the hypothesis that advanced age would be the major explanation for higher mortality among females. Adjustment for age, even though mildly reducing female mortality, maintained a significant difference. This suggested that, even though the difference in mortality observed between the sexes was partially caused by the more advanced age of females, the biological factor persisted, explaining part of the result found.

A few studies ${ }^{14,32,40,41}$ have shown that advanced age was the major prognostic factor in acute myocardial infarction, and the major factor contributing to differentiate early mortality in regard to sex. Our findings, however, are consistent with others in the literature ${ }^{14}$, suggesting that age was not the major determinant for survival in females. Likewise, 
studies by Tofler et al ${ }^{15}$ and Greenland et al ${ }^{13}$ reported that, after adjustment to age and other covariables of risk, the female sex remained as an important predictor of mortality. On the other hand, in a study with 1,551 males and 538 females with acute myocardial infarction, Dittrich et al ${ }^{42}$, after adjusting for age and risk variables, showed that the female sex is no longer a predictor of mortality, but advanced age continues to be. Maynard et $\mathrm{al}^{9}$, analyzing 4,891 patients with acute myocardial infarction in the MITI Study (Myocardial Infarction Triage and Intervention Registry), after correction for age, observed a reduction in the difference in mortality between males and females, which, nevertheless, remained significantly higher among females.

We were puzzled by the fact that diabetes mellitus was not identified as a risk variable in our study. Classical studies ${ }^{43,44}$ emphasize the strict correlation of this pathology and mortality in acute myocardial infarction. Our results may perhaps have been limited by the small number of diabetic patients ( 99 patients) in our study. Certainly the role played by diabetes mellitus could be better established with a larger sample, as its importance was marginal $(\mathrm{p}=0.06)$.

Vaccarino et al ${ }^{18}$, in a set of studies about coronary artery disease in females, reported that, in reality, the studies that used proper adjustments for risk variables, as ours did, found the greatest differences in mortality rates.

Our results confirm the hypothesis that males and fe- males may have different natural histories regarding acute myocardial infarction, the female's being a more aggressive form with a high mortality rate.

The recognition of a biological factor specific for the female sex, perhaps with a hormonal substrate, may lead to the identification of changeable factors and the adequacy of therapeutical managements to decrease the differences in the in-hospital prognosis for females with acute myocardial infarction.

In conclusion, among the 600 patients with acute myocardial infarction, we found a proportion of 2.6 males to 1 female, with in-hospital mortality 2.3 times higher in the female population.

Univariate analysis showed that in-hospital mortality was associated with the following variables: female sex, age above 70 years, presence of previous myocardial infarction, infarct localized in the anterior wall, absence of thrombolytic therapy, and presence of left ventricular dysfunction (KillipKimball heart failure classifications II to IV). Multivariate analysis showed that the variables independently related to in-hospital mortality were the following: age, female sex, previous myocardial infarction, and left ventricular dysfunction (Killip-Kimball heart failure classifications II and IV).

After adjusting for all risk variables, the female sex proved to be an independent variable related to in-hospital mortality in acute myocardial infarction.

\section{References}

1. Farmer JA, Gotto AM. Dyslipidemia and other risk factors for coronary artery disease. In: Braunwald E. Heart Disease: A Text book of cardiovascular medicine. $5^{\text {th }}$ ed Philadelphia: WB Saunders Co., 1997: 1126-60.

2. Brasil- Ministério da Saúde. Fundação Nacional de Saúde. Anuário Estatístico - IBGE 1994: 2-49, 2-123.

3. Lotufo PA. Doenças cardiovasculares no Brasil: por que altas taxas de mortalidade entre mulheres? Rev Soc Cardiol Estado de São Paulo 1996; 6: 667-71.

4. Kuhn FE, Rackley CE. Coronary artery disease in women. Arch Intern Med 1993; 153: 2626-36

5. Bueno H, Vidán MT, Almazán A, López Sendón JL, Delcán JL. Influence of sex on the short-term outcome of elderly patients with a first acute myocardial infarction. Circulation 1995; 92:1133-40.

6. Coronado BE, Griffith JL, Beshansky JR, Selkor HP. Hospital mortality in women and men with acute cardiac ischemia: A prospective multicenter study. J Am Coll Cardiol 1997; 29: 1490-6.

7. Wenger NK. Hypertension and other cardiovascular risk factors in women. AJH 1995; 8: 945-95.

8. Murabito JM, Evans JC, Larson MG, Levy D. Prognosis after the onset of coronary heart disease. Circulation 1993; 88: 2548-55.

9. Maynard C, Litwin PE, Martin JS, Weaver WD. Gender differences in the treatment and outcome of acute myocardial infarction. Results from the Myocardial Infarction Triage and Intervention Registry. Arch Intern Med 1992; 152: 972-6.

10. Robinson K, Conroy RM, Mulcahy R, Hickey N. The 15-year prognosis of a first acute coronary episode in women. Eur Heart J 1992; 13: 67-9.

11. Behar S, Gottlieb S, Hod H, Narunsky R, Benari B, for the Thrombolytic Survey Group. Influence of gender in the therapeutic management of patients with acute myocardial infarction in Israel. Am J Cardiol 1994; 73: 438-43.

12. Hochman JS, Mc Cabe CH, Stone PH, Becker RC, Cannon CP, for the TIMI Investigators. Outcome and profile of women and men presenting with acute coronary syndromes: A report from TIMI III B. J Am Coll Cardiol 1997; 30: 141-8.

13. Greenland P, Reicher-Reiss H, Goldbourt U, Behar S, and the Israeli SPRINT investigators. In-hospital and 1 year mortality in 1.524 women after myocardial infarction. Circulation 1991; 83: 484-91.

14. Demirovic J, Blackburn H, Mc Govern PG, Luepkor R, Sprafka JM, Gilberstson
D. Sex differences in early mortality after acute myocardial infarction (The Minnesota Heart Survey). Am J Cardiol 1995; 75: 1096-101.

15. Tofler GH, Stone PH, Muller JE, et al, for the MILIS Study group. Effects of gender and race on prognosis after myocardial infarction: adverse prognosis for women, particularly black women. J Am Coll Cardiol 1987; 9: 473-82.

16. Gottlieb S, Moss AJ, Mc Dermott M, Shirley E. Comparison of Posthospital survival after acute myocardial infarction in women and men. Am J Cardiol 1994; 74: 727-30.

17. Pohjola S, Siltnen P, Romo M. Five-year survival of 728 patients after myocardial infarction. Br Heart J 1980; 43: 176-83.

18. Vaccarino V, Krumholz HM, Berckman LF, Horwitz RI. Sex differences in mortality after myocardial infarction. Is there evidence for an increased risk for women? Circulation 1995; 91: 1861-71.

19. White HD, Barbash GI, Modan M, Simes J, Diaz R, for the investigators of the International Tissue Plasminogen Activator/Streptokinase mortality study. After correcting for worse baseline characteristics, women treated with thrombolytic therapy for acute myocardial infarction have the same mortality and morbidity as men except for a higher incidence of hemorrhagic stroke. Circulation 1993; 88: 2097-103.

20. Lerner DJ, Kannel WB. Patterns of coronary heart disease morbidity and mortality in the sexes. A 26-year follow-up of the Framingham population. Am Heart J 1986; 111: 382-90.

21. Johansson S, Bergstrand R, Ulvenstam G, et al. Sex differences in preinfarction characteristics and long-term survival among patients with myocardial infarction. Am J Epidemiol 1984; 119: 610-23.

22. Gottlieb S, Boykov V, Zahger D, Balkin J, Hod H, for the Israeli Thrombolytic Survey Group. Smoking and prognosis after myocardial infarction in the trombolytic era (Israeli Thrombolitic National Survery) J Am Coll Cardiol 1996; 28 : 1506-13.

23. Klein HH, Hengstenberg C, Peuckert M, Jürgensen R. Comparison of death rates from acute myocardial infarction in a single hospital in two different periods (1977-1978 versus 1988-1989). Am J Cardiol 1993; 71: 518-23.

24. Jenkins JS, Flaker GC, Noete B, et al. Causes of higher in-hospital mortality in women than in men after acute myocardial infarction. Am J Cardiol 1994; 73: 319-22. 
25. Bassan R, Potsch A, Pimenta L, et al. Mortalidade hospitalar no infarto agudo do miocárdio: é possível prever utilizando dados de admissão? Arq Bras Cardiol 1996; 67: 149-58.

26. Lincoff AM, Califf RM, Ellis SG, et al, for the Thrombolysis and Angioplasty in Myocardial Infarction study group. Thrombolytic therapy for women with myocardial infarction: is there a gender gap? J Am Coll Cardiol 1993; 22: 1780-7.

27. Behar S, Reicher-Reiss H, Abinader E, et al. The prognostic significance of angina pectoris preceding the occurrence of a first acute myocardial infarction in 4.166 consecutive hospitalized patients. Am Heart J 1992; 123: 1481-6.

28. Pagley PR, Yarzebski J, Goldberg R, et al. Gender differences in the treatment of patients with acute myocardial infarction. Arch Intern Med 1993; 153: 625-9.

29. Green LA, Ruffin MT. Differences in management of suspected myocardial infarction in men and women. J Fam Parct 1993; 36: 389-93.

30. Cerqueira MD, Maynard C, Ritchie JL, Davis KB, Kennedy JW. Long-term survival in 618 patients from the Western Washington Streptokinase in Myocardial Infarction Trials. J Am Coll Cardiol 1992; 20: 1452-9.

31. Maynard C, Althouse R, Cerqueira M, Olsufka M, Kennedy JW. Underutilization of thrombolytic therapy in eligible women with acute myocardial infarction. Am J Cardiol 1991; 68: 529- 30.

32. The Gusto investigators. An international randomized trial comparing four thrombolytics strategies for acute myocardial infarction. N Engl J Med, 1993; 329: 673-82.

33. Gruppo italiano per lo studio della sopravvivenza nell' infarto miocardioco GISSI-2: in hospital mortality and clinical course of 20.891 patients with suspected acute myocardial infarction randomized between alteplase and streptoquinase with or without heparin. Lancet 1990; 336: 71-5.

34. ISIS-2 (Second Internation Study of infarct survival) Collaborative group.
Randomized trial of intravenous streptokinase, oral aspirin, both, or neither among 17.187 cases of susppected acute myocardial infarction. Lancet 1988; ii: 349-60.

35. Wilcox RG, von der Lippe G, Olsson CG, Jensen G, Skene AM, Hampton JR. Trial of tissue plasminogen activator for mortality reduction in acute myocardial infarction. Anglo-Scandinavian Study of Early Thrombolysis (ASSET). Lancet 1988; ii: 525-30.

36. Becker RC, Terrin M, Ross R, et al and the Trombolysis in Myocardial Infarction Investigators. Ann Intern Med 1994; 120: 635-45.

37. Pilote L, Heatky MA. Attitudes of women toward hormone therapy and prevention of heart disease. Am Heart J 1995; 129: 1237-8.

38. Lee KL, Woodlief LH, Topol EJ, et al. Predictors of 30-day mortality in the era of reperfusion for acute myocardial infarction. Results from internacional trial of 41.021 patients. Circulation 1995; 91: 1659-68.

39. Norris RM, Brandt PWT, Caughey DE, Lee AJ, Scott PJ. A new coronary prognostic index. Lancet 1969; i: 274-8.

40. Piérard LA, Dubois C, Albert A, Smeets JP, Kulbertus HE. Prediction of mortality after myocardial infarction by simple clinical variables recorded during hospitalization. Clin Cardiol 1989; 12: 500-4.

41. Sahasakul Y, Chaithiraphan S, Panchavinnin P, et al. Multivariate analyses in the prediction of death in hospital after myocardial infartion. Br Heart J 1990; 64: 182-5.

42. Dittrich H, Gilpin E, Nocod P, Cali G, Henning H, Ross J Jr. Acute myocardial infarction in women:influence of gender on mortality and prognostic variables. Am J Cardiol 1988; 62: 1-7.

43. Wenger NK. Gender differences in coronary risk and risk factors. In: Prevention of heart disease in women: special issues 1997; 387-411.

44. Carvalho ET, Alencar YMG, Liberman S. Fatores de risco de aterosclerose na mulher após a menopausa. Arq Bras Cardiol 1996; 66: 37- 48. 